\title{
Traffic \& Pedestrian Studies of Selected Routes in Nagpur City
}

\author{
${ }^{* 1}$ Kameshwar Rao Tallapragada, ${ }^{2}$ Divya Chandak, ${ }^{3}$ Yash Rathi, ${ }^{4}$ Rajat Raghuwanshi \\ 1,2,3,4 Shri Ramdeobaba College of Engineering and Management, Nagpur \\ Email:raotk@rknec.edu, chandakdp@rknec.edu,rathiym@rknec.edu,rajatraghu1998@gmail.com
}

Received: 14th November 2019, Accepted: 10th February 2020, Published: 29th February 2020

\begin{abstract}
Traffic flow is one of the major issues that most of the metropolitan cities are facing in spite of measures being taken to ease and reduce it. Traffic congestion in the recent past years, has emerged as one of the main challenge for engineers, planners and policy makers in urban areas. Also it is a challenge to provide efficient road width, footpath width, and signal time for the increasing demand with the limited resources available. In this research traffic flow and pedestrian facilities of selected routes in Nagpur city has been studied. This research investigates those sections of the Nagpur city which are considered among the busiest roads.
\end{abstract}

Key words

Traffic Flow, Pedestrian Facilities, Traffic Signal, Footpath, Traffic Congestion.

\section{Introduction}

Nagpur, being a developing metro, has got a traffic density which is growing at a rapid pace. The increasing number of two wheelers, four wheelers along with the public transport and pedestrians poses a severe issue for the smooth and congestion-free movement of the traffic. It is seen that no effective traffic management has been carried out at the heavily crowded areas like Variety square, Law College Square, Shankar Nagar Square, Ravi Nagar Square, Lokmat Square, etc. Effective designs of flyovers have been constructed keeping in view the density of the flow of the traffic and the roads underneath it.

One of the major reasons is the complexity involved in modelling pedestrian behaviour. Complexity arises from multiple parameters which affect the pedestrian crossing behaviour and are very difficult to identify. At signalized intersections, pedestrian travel is extremely high with lesser amount of safety measures provided to them. At gross level one will analyze the fundamental flow parameters like speed, density of pedestrian motion and at microscopic level one may track the paths followed by individual pedestrians while moving respectively. From this it is clear that the pedestrian may create their own paths in their journey trip.

Coming to the pedestrian crosswalks there were several cross walks like zebra crossing are designed for a road, provide gainful work to assist the pedestrians to move from one side to the opposite aspect of road, and which plays a significant role in the mobility and safety mode of signalized intersections. In some other places like where the busy traffic takes place, pedestrian choose the mid blocks to cross the road. But there's no safety as compared to signalized intersections. Even several pedestrian crosswalks area required in these midblock sections when pedestrian has to walk too much distance to either ends of divider to cross the road.

A number of traffic and transportation surveys were conducted as a part of the study in order to assess the passenger and goods movement pattern, travel characteristics, [1][2][3][4][5][6][7][8]pedestrian and parking characteristics and the available infrastructure facilities within the study area. The data collection activities included classified traffic volume counts, PCU, speed, footpath analysis, parking surveys, pedestrian surveys.

\section{Objective of Work}

- To study the traffic flow.

- parking facilities

- Pedestrian facilities available.

\section{Review of Literature}

Sachin Dass et al (2006) have reported that with an increase in the motor vehicular traffic and the corresponding increase in the corresponding increase in the congestion and increase in the road accidents. [12] The importance for improvement of the pedestrian facilities has assumed great significance.

Wen Dong and Alex Pentland (2008) have reported their results on the high resolution tracking data for hundreds to thousands of urban vehicles, [14] as well as the availability of digitized map data, provide urban planners unprecedented opportunities for better understanding urban motor vehicle transportation and for better exploiting the knowledge thereof.

Rajat Rastogi, et al, (2011), studied the Pedestrian Speeds at Midblock Crossings. Speed while crossing a road depends on various characteristics related to pedestrians, traffic, and physical features of the road. [10] A few of these characteristics are age, gender, pedestrian movement singly or in a group, traffic volume, size of the urban area, and width of the road.

Marisamynathan, Vedagiri Perumal (2014), [9] have analysed the crossing behaviour of pedestrians like crossing speed, compliance with signal, and pedestrian-vehicular interaction under mixed traffic conditions. 
Rajko Horvat, Goran Kos, Marko Ševrović (2015), [11] studied the design elements of road infrastructure such as, Road type and number of traffic lanes, cross-sectional profile. A Scientifically model has been developed to explore the traffic flows to the exact of traffic flows in urban areas.

Tejas Rawal, V. Devadas (2015), have studied on the world wide recurring problem in road traffic congestion which was acutely faced by almost all major cities.[13]

\section{Study Area}

The study area is limited to three routes of Nagpur.

1. From Law college square to Shankar Nagar

2. From Lokmat square to Variety square

3. From Ravi nagar square to Ram Nagar square

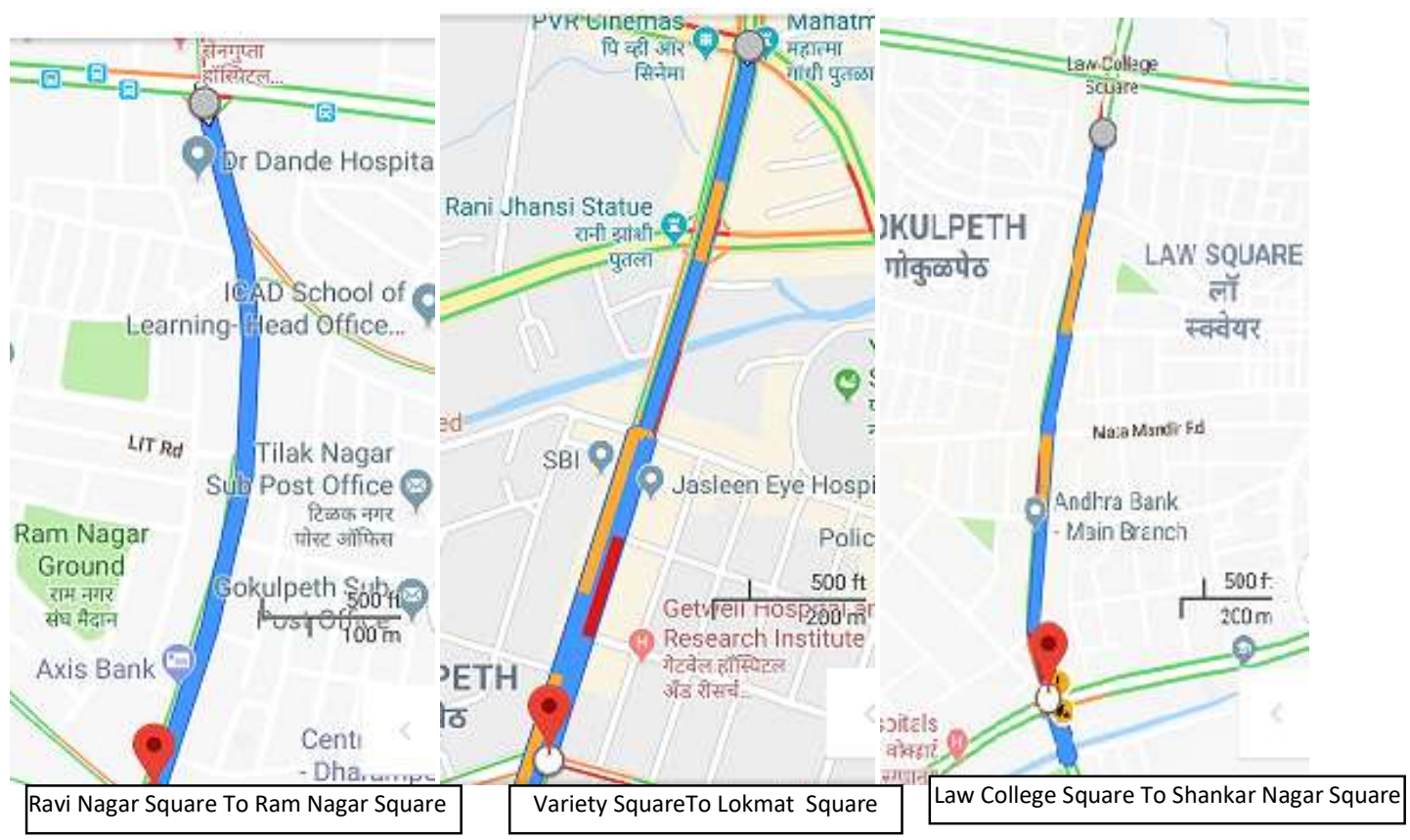

Methodology

Figure 1: Google Map of Three Routes

Traffic surveys and pedestrian studies were conducted. Pedestrian facilities were studied and all the data were analysed using Microsoft Excel.

\section{Results and Discussion}

Traffic volume data has been collected in all the routes of study area presented in the Figure 2, Figure 3, Table 1 and Table 2. Peak hour traffic volume is collected in the morning from 10 a.m. to 12 noon and in the evening from 4 p.m. to 6 p.m. Similarly Non peak hour traffic volume is collected from 1 p.m. to 4 p.m. Similarly total pedestrians using or not using footpath was also collected during the same peak and non-peak hours. Total footpath area and obstruction in footpath area was also studied, the data of the same is shown in Figure 4, Figure 5, Table 3 and Table 4. The obstruction area of footpath varies from $10 \%$ to $60 \%$. Due to which the pedestrians are forced to use road which is meant for vehicles. This directly affects the speed of vehicles. The average speeds of two and four wheelers have fallen respectively to $25 \mathrm{KMPH}$ and $22 \mathrm{KMPH}$. Also it observed that pedestrians not using footpath is almost ranges from $80 \%$ to $90 \%$. This may be due to encroachment of footpath by roadside vendors and obstructions in footpath. 


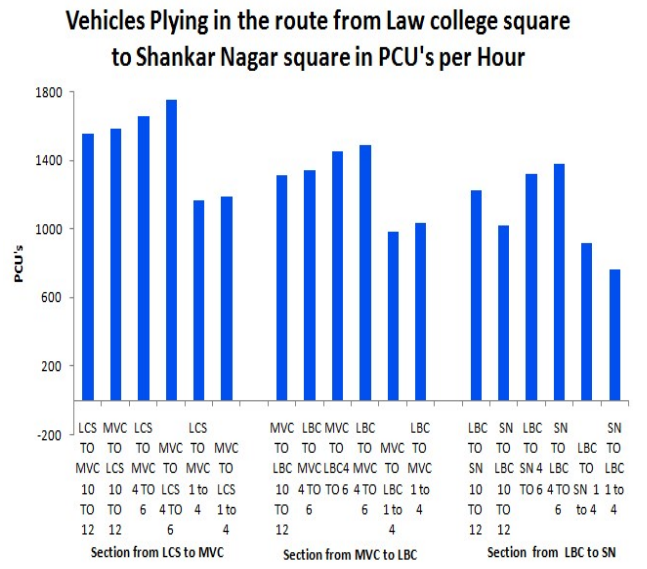

Figure 2: Sample Graph showing total Vehicles Plying (PCU's)

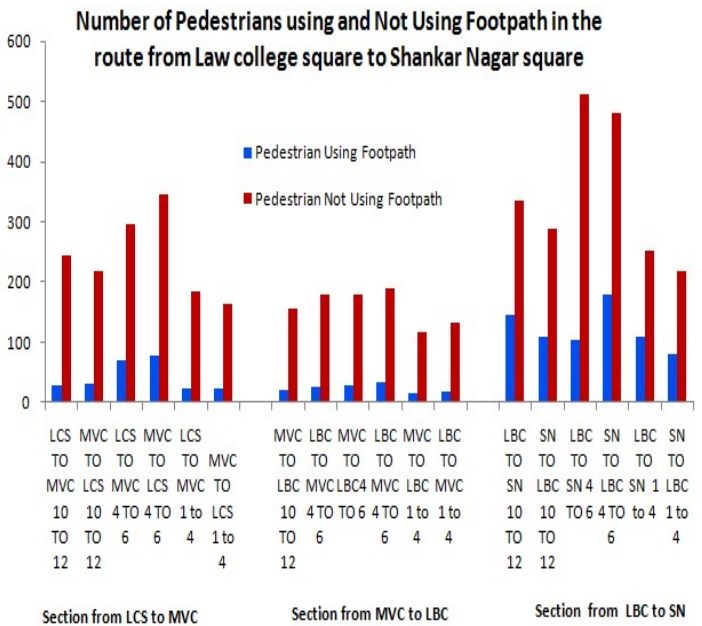

Figure 4: Sample Graph showing Utilization of Footpath by Pedestrians

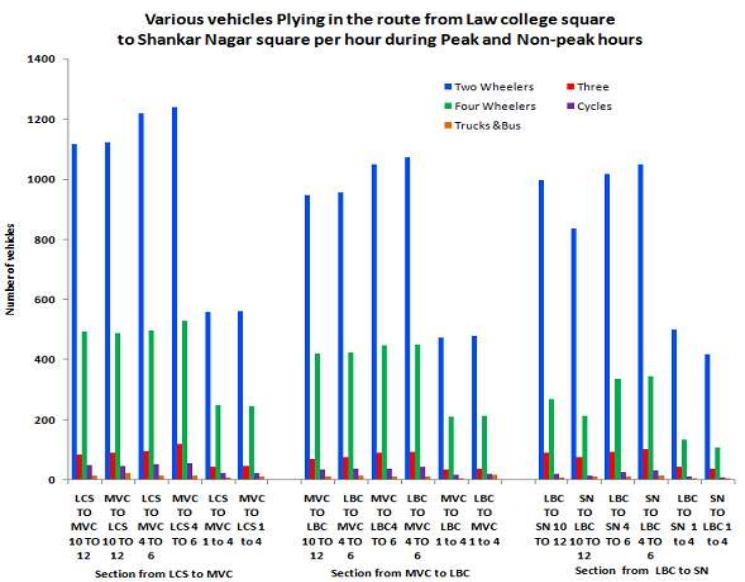

Figure 3: Sample Graph showing Vehicles Plying

Footpath utilised in the route from Law college

square to Shankar Nagar square

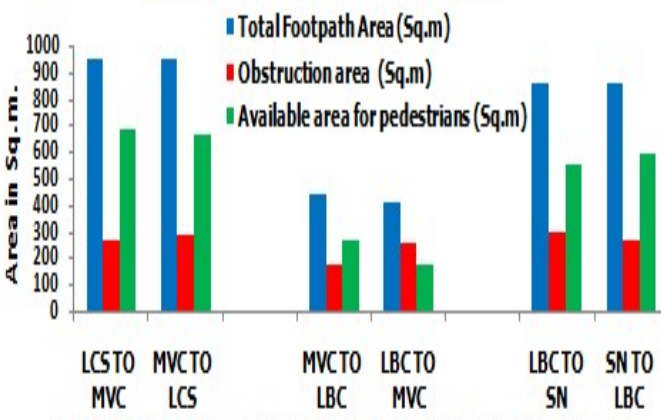

SECTION FROM LAW COLLEGE SQUARE TO SHANKAR SQUARE AND VICEVERSA

Figure 5: Sample Graph showing Availability and Obstruction Area of Footpath

\begin{tabular}{|l|c|c|c|c|c|c|c|}
\hline $\begin{array}{c}\text { Route from Lokmat } \\
\text { square to Variety } \\
\text { square }\end{array}$ & $\begin{array}{c}\text { Two } \\
\text { Wheelers }\end{array}$ & $\begin{array}{c}\text { Three } \\
\text { wheelers }\end{array}$ & $\begin{array}{c}\text { Four } \\
\text { Wheelers }\end{array}$ & Cycles & $\begin{array}{c}\text { Trucks } \\
\text { \& } \\
\text { Buses }\end{array}$ & $\begin{array}{c}\text { Total } \\
\text { Volume } \\
\text { (in } \\
\text { vehicles) }\end{array}$ & $\begin{array}{c}\text { Total } \\
\text { Volume } \\
\text { (in } \\
\text { PCU's) }\end{array}$ \\
\hline LS TO PS 10 TO 12 & 3276 & 748 & 1148 & 126 & 110 & 5408 & 2697 \\
\hline PS TO LS 10 TO 12 & 3420 & 940 & 1023 & 145 & 198 & 5726 & 2981 \\
\hline LS TO PS 4 TO 6 & 3854 & 764 & 1040 & 98 & 102 & 5858 & 2861 \\
\hline PS TO LS 4 TO 6 & 3792 & 846 & 1326 & 114 & 116 & 6194 & 3081 \\
\hline LS TO PS 1 to 4 & 2456 & 561 & 861 & 94 & 82 & 4054 & 2022 \\
\hline PS TO LS 1 to 4 & 2565 & 705 & 767 & 108 & 148 & 4293 & 2235 \\
\hline PS TO JRS 10 TO & 3490 & 823 & 951 & 107 & 117 & 5488 & 2757 \\
\hline JRS TO PS 10 TO & 3156 & 795 & 923 & 101 & 103 & 5078 & 2574 \\
\hline PS TO JRS 4 TO 6 & 3875 & 789 & 1079 & 89 & 92 & 5924 & 2901 \\
\hline JRS TO PS 4 TO 6 & 3945 & 812 & 1145 & 95 & 97 & 6094 & 2990 \\
\hline PS TO JRS 1 to 4 & 2617 & 617 & 713 & 80 & 87 & 4114 & 2067 \\
\hline JRS TO PS 1 to 4 & 2367 & 596 & 692 & 75 & 77 & 3807 & 1929 \\
\hline \hline JRS TO VS 10 TO & 3820 & 1620 & 946 & 156 & 293 & 6835 & 3879 \\
\hline VS TO JRS 10 TO & 3712 & 1570 & 897 & 167 & 274 & 6620 & 3745 \\
\hline
\end{tabular}




\begin{tabular}{|l|c|c|c|c|c|c|c|} 
JRS TO VS 4 TO 6 & 3492 & 1562 & 1380 & 128 & 310 & 6872 & 3928 \\
\hline VS TO JRS 4 TO 6 & 3516 & 1617 & 1423 & 132 & 306 & 6994 & 4010 \\
\hline JRS TO VS 1 to 4 & 2865 & 1215 & 709 & 117 & 219 & 5125 & 2908 \\
\hline VS TO JRS 1 to 4 & 2784 & 1177 & 672 & 125 & 205 & 4963 & 2808 \\
\hline
\end{tabular}

Table 1: Traffic Volume in the Route from Lokmat Square to Variety Square

\begin{tabular}{|l|c|c|c|c|c|c|c|}
\hline $\begin{array}{c}\text { Route from Ravi } \\
\text { Nagar square to } \\
\text { Ram Nagar square }\end{array}$ & $\begin{array}{c}\text { Two } \\
\text { Wheelers }\end{array}$ & $\begin{array}{c}\text { Three } \\
\text { wheelers }\end{array}$ & $\begin{array}{c}\text { Four } \\
\text { Wheelers }\end{array}$ & Cycles & $\begin{array}{c}\text { Trucks } \\
\text { \& } \\
\text { Buses }\end{array}$ & $\begin{array}{c}\text { Total } \\
\text { Volume } \\
\text { (in } \\
\text { vehicles) }\end{array}$ & $\begin{array}{c}\text { Total } \\
\text { Volume } \\
\text { (in } \\
\text { PCU's) }\end{array}$ \\
\hline RS TO LITR 10 TO & 1489 & 229 & 728 & 32 & 42 & 2520 & 1204 \\
\hline LITR TO RS 10 TO & 1372 & 214 & 718 & 28 & 36 & 2368 & 1133 \\
\hline RS TO LITR 10 TO & 1836 & 258 & 840 & 36 & 48 & 3018 & 1427 \\
\hline LITR TO RS 4 TO & 1921 & 261 & 872 & 39 & 54 & 3147 & 1485 \\
\hline RS TO LITR 10 TO & 1377 & 193 & 630 & 27 & 36 & 2263 & 1069 \\
\hline LITR TO RS 1 to 4 & 1442 & 214 & 520 & 22 & 38 & 2236 & 1061 \\
\hline & & & & & & & \\
\hline LITR TO RNS 10 & 1612 & 248 & 847 & 36 & 49 & 2792 & 1337 \\
\hline RNS TO LITR 10 & 1479 & 297 & 812 & 36 & 51 & 2675 & 1321 \\
\hline LITR TO RNS 4 & 1975 & 315 & 978 & 42 & 54 & 3364 & 1612 \\
\hline RNS TO LITR 4 & 2079 & 342 & 907 & 41 & 63 & 3432 & 1653 \\
\hline LITR TO RNS 1 to & 1487 & 214 & 689 & 31 & 39 & 2460 & 1165 \\
\hline RNS TO LITR 1 to 4 & 1587 & 247 & 589 & 27 & 48 & 2498 & 1195 \\
\hline
\end{tabular}

Table 2: Traffic Volume in the Route from Ravi Nagar Square to Ram Nagar Square

\begin{tabular}{|c|c|c|c|c|c|}
\hline $\begin{array}{c}\text { Route From Lokmat } \\
\text { Square To Variety } \\
\text { Square }\end{array}$ & $\begin{array}{l}\text { Pedestrian } \\
\text { Using } \\
\text { Footpath }\end{array}$ & $\begin{array}{l}\text { Pedestrian } \\
\text { Not Using } \\
\text { Footpath }\end{array}$ & $\begin{array}{c}\text { Route From Ravi } \\
\text { Nagar Square To } \\
\text { Ram Nagar Square }\end{array}$ & $\begin{array}{l}\text { Pedestrian } \\
\text { Using } \\
\text { Footpath }\end{array}$ & $\begin{array}{l}\text { Pedestrian } \\
\text { Not Using } \\
\text { Footpath }\end{array}$ \\
\hline LS TO PS 10 TO 12 & 20 & 1110 & RS TO LITR 10 & 12 & 248 \\
\hline PS TO LS 10 TO 12 & 23 & 1117 & LITR TO RS 10 & 15 & 236 \\
\hline LS TO PS 4 TO 6 & 28 & 916 & RS TO LITR 4 TO & 24 & 239 \\
\hline PS TO LS 4 TO 6 & 27 & 804 & LITR TO RS 4 TO & 23 & 243 \\
\hline LS TO PS 1 to 4 & 15 & 832 & RS TO LITR 1 to 4 & 10 & 170 \\
\hline PS TO LS 1 to 4 & 17 & 838 & LITR TO RS 1 to 4 & 12 & 178 \\
\hline PS TO JRS 10 TO 12 & 28 & 897 & LITR TO RNS 10 & 18 & 287 \\
\hline JRS TO PS 10 TO 12 & 19 & 742 & RNS TO LITR 10 & 21 & 264 \\
\hline PS TO JRS 4 TO 6 & 31 & 819 & LITR TO RNS 4 & 25 & 289 \\
\hline JRS TO PS 4 TO 6 & 39 & 925 & RNS TO LITR 4 & 27 & 281 \\
\hline PS TO JRS 1 to 4 & 21 & 672 & LITR TO RNS 1 & 16 & 199 \\
\hline JRS TO PS 1 to 4 & 14 & 556 & RNS TO LITR 1 to & 19 & 197 \\
\hline JRS TO VS 10 TO 12 & 1200 & 2198 & & & \\
\hline VS TO JRS 10 TO & 1324 & 2028 & & & \\
\hline JRS TO VS 4 TO 6 & 1500 & 2134 & & & \\
\hline VS TO JRS 4 TO 6 & 1489 & 2256 & & & \\
\hline JRS TO VS 1 to 4 & 900 & 1648 & & & \\
\hline VS TO JRS 1 to 4 & 993 & 1521 & & & \\
\hline
\end{tabular}

Table 3: Pedestrian Using or Not Using Footpath in the two routes 


\begin{tabular}{|c|c|c|c|c|c|c|c|}
\hline $\begin{array}{c}\text { Route } \\
\text { From } \\
\text { Lokmat } \\
\text { Square } \\
\text { To } \\
\text { Variety } \\
\text { Square }\end{array}$ & $\begin{array}{c}\text { Total } \\
\text { Footpath } \\
\text { Area } \\
\text { (Sq.m) }\end{array}$ & $\begin{array}{c}\text { Obstruction } \\
\text { area } \\
\text { (Sq.m) }\end{array}$ & $\begin{array}{l}\text { Available } \\
\text { area for } \\
\text { pedestrians } \\
\text { (Sq.m) }\end{array}$ & $\begin{array}{c}\text { Route From } \\
\text { Ravi Nagar } \\
\text { Square To } \\
\text { Ramnagar } \\
\text { Square }\end{array}$ & $\begin{array}{c}\text { Total } \\
\text { Footpath } \\
\text { Area } \\
\text { (Sq.m) }\end{array}$ & $\begin{array}{l}\text { Obstruction } \\
\text { area } \\
\text { (Sq.m) }\end{array}$ & $\begin{array}{c}\text { Available } \\
\text { area for } \\
\text { pedestrians } \\
\text { (Sq.m) }\end{array}$ \\
\hline $\begin{array}{ll}\text { LS } & \text { TO } \\
\text { PS } & \\
\end{array}$ & 790.24 & 341 & 449.24 & RS TO LITR & 693 & 338 & 355 \\
\hline $\begin{array}{ll}\text { PS } & \text { TO } \\
\text { LS } & \\
\end{array}$ & 788.44 & 441.86 & 346.58 & LITR TO RS & 745.5 & 323.4 & 422.1 \\
\hline $\begin{array}{ll}\text { PS } & \text { TO } \\
\text { JRS } & \end{array}$ & 493.06 & 88.34 & 404.72 & $\begin{array}{l}\text { LITR TO } \\
\text { RNS }\end{array}$ & 670 & 120 & 550 \\
\hline $\begin{array}{ll}\text { JRS } & \text { TO } \\
\text { PS } & \\
\end{array}$ & 507.32 & 252.87 & 254.45 & $\begin{array}{l}\text { RNS TO } \\
\text { LITR }\end{array}$ & 790.24 & 341 & 449.24 \\
\hline $\begin{array}{ll}\text { JRS } & \text { TO } \\
\text { VS } & \\
\end{array}$ & 535.35 & 200.82 & 334.53 & & & & \\
\hline $\begin{array}{ll}\text { VS } & \text { TO } \\
\text { JRS } & \end{array}$ & 507.22 & 266.7 & 240.52 & & & & \\
\hline
\end{tabular}

Table 4: Total Footpath Area Obstruction due to Encroachments and Other Factors in the Two Routes

\section{Conclusion}

- It has been observed that out of the three road routes, maximum traffic is from Variety Square to Jhansi Rani Square. This is because it is considered as the most crowded area in Nagpur city.

- Since this region is a Central Business Area (CBA), here traffic count is higher as compared to the remaining two stretches.

- The pedestrian count is maximum on Variety Square to Jhansi Rani Square stretch. Due to encroachments, the complete footpath stretch is not available to the pedestrians. There are also various obstructions on the foot path which made pedestrians to step up and step down of footpath.

- On all the three routes it has observed that the footpath tiles were broken on many places, and at some points, the length of broken footpath is greater than 20 meters.

- Trees, electric poles, telephone DP boxes, shopkeepers' encroachments, removal of paver tiles/blocks and various openings were present in between the footpath which becomes the obstructions while walking through it.

- It has been observed that percentage area availability of footpath for the pedestrians is very less. So pedestrians have been forced to use road in place of footpath.

- On all the three routes, it was observed that vehicles were parked in no parking zone and also in haphazard ways. Also the pedestrians were using road due to encroachment of footpaths and obstructions on the footpaths. These are the reasons which resulted in decreased average speed of the vehicles plying on the road.

- Routine maintenance of the footpath with strict removal of encroachment will lead to smooth movement of the pedestrians.

- Pedestrians are encouraged to use footpaths and they are strictly warned not to use the road, which will result in full availability of width of road for vehicles and smooth traffic flow of vehicles.

- Strict and structural parking area will enhance the speed of vehicles.

\section{References}

1. Department of Traffic and Transport Planning. Royal Institute of Technology, S-100 44 Stockholm, Sweden, Pedestrian safety at traffic signals, (Received 15 November 1984; in revised form 8 March 1989).

2. Google Maps.

3. IRC : 69 - 1997 Space Standard for roads in Urban areas.

4. IRC : 86 - 1983 Geometric Design Standard for urban roads in plains.

5. IRC : 70 - 1977 Guidelines on Regulations and control of mixed traffic in urban road areas.

6. IRC : 103 - 1988 Guidelines for Pedestrian Facilities.

7. IRC : 106 - 1990 Guideline for capacity of urban road in plain areas.

8. IRC SP 12 - 1973 Tentative recommendations on the provisions of parking space for urban areas. 
9. Marisamynathan, Vedagiri Perumal., Pedestrian crossing behaviour at signalized intersections, Journal of Traffic and Transportation Engineering (English Edition), Volume 1, Issue 2, April 2014, Pages 103-110.

10. Rajat Rastogi; Satish Chandra; J. Vamsheedhar; and Vivek R. Das, Pedestrian Speeds, April 18, 2011

11. Rajko Horvat, Goran Kos, Marko Ševrović.,Traffic flow modelling on the road network , Vol. 22, no. 2, 2015.

12. Sachin Dass, Dhirendra Singhal, Praveen Aggarwal (CED, DCRUST, Murthal (CED, NIT Kurukshetra), Pedestrian Behaviour on Roads, 2006.

13. Tejas Rawal, V. Devadas, journal of development management and communication, Intelligent Transport Systems in India, Vol. 2, no. 3, (2015), ISSN 2348 - 7739.

14. Wen Dong and Alex Pentland (2008), Network Analysis of Road Traffic with Vehicle Tracking Data. 